\title{
Effect of Loan to Deposit Ratio (LDR) and BOPO on Profitability on PT BPR Bali Ambassador for the Year 2014-2018
}

\author{
Ni Made Rusmini ${ }^{a, 1, *}$, Ade Maharini Adiandari ${ }^{\text {b,2 }}$ \\ ${ }^{a}$ Fakultas Ekonomi Universitas Ngurah Rai, Jalan Padma, Penatih, Kecamatan Denpasar Timur, Kota Denpasar, 80238, Provinsi \\ Bali, Indonesia. \\ ${ }^{\mathrm{b}}$ Fakultas Ekonomi Universitas Ngurah Rai, Jalan Padma, Penatih, Kecamatan Denpasar Timur, Kota Denpasar, 80238, Provinsi \\ Bali, Indonesia. \\ ${ }^{1}$ maderusmini78@gmail.com * \\ * corresponding author
}

\section{ARTICLE INFO}

\section{Article history}

Received

Revised

Accepted

Keywords

Loan to Deposit Ratio;

Operating Cost Operating

Income and profitability

\section{ABSTRACT}

Profitability is the ability or ability of the bank to obtain profits or profits. The problem of profitability is very important because the bank's income is the main target that must be achieved by the bank because the main purpose of the bank is to achieve profit or profit. The higher the bank's profitability, the better the bank's performance. The formulation of the problem in this study is: whether the Loan to Deposit Ratio (LDR) and Operational Income Operating Costs (BOPO) simultaneously or partially affect the profitability of PT. BPR. Duta Bali for the period 2014-2018? This study aims to determine the effect simultaneously or partially between the Loan to Deposit Ratio (LDR) and Operational Income Operating Costs (BOPO) to Profitability at PT. BPR. Duta Bali for the period 2014-2018. The technique of taking samples in this study uses judgmental sampling. Data were analyzed using classical assumption test, multiple linear regression analysis, Determination analysis, simultaneous significance test $(F$-test) and partial significance test (t-test). The results of the study indicate that the Loan to Deposit Ratio has a positive and insignificant effect on Profitabiltas. Operational Costs Operational Income has a significant positive effect on profitability. Loan to Deposit Ratio and Operational Costs Operational Income has a significant effect on profitability at PT. BPR. Duta Bali for the period 2014-2018.

\section{PENDAHULUAN}

Pembangunan sektor keuangan, terutama perubahan susunan atau struktur perbankan di Indonesia sangat diharapkan bisa membawa perubahan yang positif bagi perekonomian nasional. Lembaga keuangan, khususnya perbankan memiliki peran yang sangat penting terhadap pergerakan roda perekonomian Indonesia. Lembaga keuangan harus bisa optimal dalam menjalankan fungsi utamanya sebagai lembaga intermediasi keuangan. Peranan utama lembaga keuangan adalah sebagai lembaga intermediasi keuangan (financial intermediary) adalah mengalihkan dana dari pihak yang kelebihan dana (surplus) kepada pihak yang kekurangan dana (deficit) di samping menyediakan jasa-jasa keuangan lainnya.

Menurut UU No.10 Th 1998, lembaga keuangan bank dibedakan menjadi dua, yaitu bank umum dan Bank Perkreditan Rakyat. Bank umum adalah bank yang melaksanakan kegiatan usaha secara konvensional atau berdasarkan prinsip syariah yang dalam kegiatannya memberikan jasa dalam lalu lintas pembayaran, sedangkan Bank Perkreditan Rakyat merupakan bank yang melaksanakan kegiatan usaha secara konvensional atau berdasarkan prinsip syariah yang dalam kegiatannya tidak memberikan jasa dalam lalu lintas pembayaran. Tantangan Bank Perkreditan Rakyat (BPR) dinilai semakin ketat. Hal itu terutama menghadapi gempuran bank-bank umum yang sudah masuk wilayah mikro, dengan tawaran suku bunga pinjaman lebih rendah dan fasilitas simpanan beragam. Berkaitan dengan hal tersebut, Bank Perkreditan Rakyat (BPR) harus bisa menjaga kepercayaan masyarakat dengan memperlihatkan tingkat kesehatan bank dan kestabilan likuiditas tetap aman serta bisa mencapai tingkat profitabilitas yang maksimum.

Profitabilitas perbankan adalah kesanggupan atau kemampuan bank dalam memperoleh laba (Hasibuan, 1996:109). Kinerja keuangan Bank Perkreditan Rakyat (BPR) bisa diukur melalui analisis terhadap laporan keuangan perusahaan. Analisis laporan keuangan tersebut untuk mengetahui tingkat profitabilitas dan tingkat risiko atau tingkat kesehatan BPR. Rasio Profitabilitas yang digunakan untuk 
mengukur pencapaian laba adalah Return on Asset (ROA) yaitu merupakan perbandingan laba sebelum pajak terhadap total asset. Semakin besar rasio ROA maka semakin besar pendapatan laba yang berarti kinerja bank semakin baik.

Untuk mencapai laba yang diinginkan, maka bank harus mampu memanfaatkan dana yang diperoleh dengan baik dan menyalurkan kembali dana tersebut baik berupa simpanan di bank lain maupun berupa kredit dan tentunya tetap memperhatikan kualitas kredit yang diberikan. Jika bank tidak mampu menyalurkan kredit sementara dana yang terhimpun banyak maka akan menyebabkan bank tersebut rugi (Kasmir, 2002). Untuk mengukur besarnya kredit yang diberikan dapat menggunakan rasio Loan to Deposit Ratio (LDR) yaitu membandingkan antara total kredit yang disalurkan dengan total dana pihak ketiga (DPK) yang dihimpun oleh bank. Menurut Peraturan Bank Indonesia Nomor 17/11/PBI/2015 menyatakan bahwa batas bawah LDR sebesar $78 \%$ dan batas atasnya sebesar $92 \%$. Besarnya kredit yang akan disalurkan menentukan keuntungan bank. Apabila jumlah kredit yamg disalurkan oleh bank meningkat, maka profitabilitas bank akan semakin meningkat juga.

Penelitian yang dilakukan oleh Ida Ayu Adiatmayani Peling (2018) dan Ida Bagus Panji Sedana (2018) menemukan hasil bahwa LDR berpengaruh positif dan signifikan terhadap ROA. Hasil tersebut berlawanan dengan hasil penelitian yang dilakukan oleh Slamet Fajar (2017) dan Sunarto (2017). Penelitian ini menghasilkan LDR tidak berpengaruh terhadap ROA.

Selain penyaluran kredit, bank juga harus memperhatikan efisiensi biaya operasional. Efisiensi operasional juga merupakan salah satu faktor risiko operasional yang mempengaruhi profitabilitas. Risiko operasional menurut Fahmi (2010:54), adalah merupakan risiko yang umumnya bersumber dari masalah internal perusahaan, dimana risiko ini terjadi disebabkan oleh lemahnya sistem kontrol manajemen (management control system) yang dilakukan oleh pihak internal perusahaan. Untuk mencapai profitabilitas yang maksimum bank juga harus memperhatikan efisiensi biaya operasional. Rasio yang digunakan untuk mengukur efisien atau tidaknya kegiatan opersionalnya, bank dapat menggunakan rasio perbandingan antara beban Operasional terhadap pendapatan operasional (BOPO).

Menurut hasil penelitian Ni Wayan Wita Capriani (2016) dan I Made Dana (2016) risiko operasional berpengaruh negatif signifikan terhadap profitabilitas. Begitu pula dengan hasil penelitian Ida Ayu Adiatmayani Peling (2018) dan Ida Bagus Panji Sedana (2018) risiko operasional yang diukur dengan rasio BOPO berpengaruh negatif dan signifikan terhadap ROA. Sedangkan penelitian Muhammad Fahrul Rosi Syafi'I (2016) menunjukkan hasil bahwa BOPO berpengaruh positif dan signifikan terhadap profitabilitas.

Perbedaan hasil temuan penelitian tentang pengaruh LDR dan pengaruh BOPO terhadap profitabilitas, selain itu karena melihat pentingnya penilaian terhadap kinerja keuangan bank agar dapat memaksimalkan profitabilitas, maka peneliti perlu mengkaji kembali agar memperjelas lagi tentang bagaimana pengaruh LDR dan pengaruh BOPO terhadap profitabitas.

Pada penelitian ini, penulis mengambil lokasi pada PT. BPR. Duta Bali, yang berkedudukan di Jalan Raya Sesetan No.48 Denpasar. Sebagaimana layaknya manusia, dimana kesehatan merupakan hal yang paling penting di dalam kehidupannya, begitu juga halnya dengan PT. BPR. Duta Bali, wajib memelihara tingkat kesehatan bank sesuai dengan ketentuan yang berlaku.

Dari penelitian awal yang penulis lakukan tentang perkembangan rasio keuangan pada PT. BPR. Duta Bali, maka penulis dapat menyajikan data-data sebagai berikut:

\section{Tabel 1}

Perkembangan Rasio Keuangan PT. BPR. Duta Bali di Denpasar Periode 2014-2018

\begin{tabular}{|c|c|c|c|c|c|}
\hline Perkembangar & Rasio Keua & $\begin{array}{l}\text { 2014-201s } \\
\text { PT. BPF }\end{array}$ & R. Duta Bal & di Denpasa & r Periode \\
\hline \multirow{2}{*}{$\begin{array}{c}\text { KETERANG } \\
\text { AN }\end{array}$} & \multicolumn{5}{|c|}{ TAHUN } \\
\hline & $2014(\%)$ & $2015(\%)$ & $2016(\%)$ & $2017(\%)$ & $2018(\%)$ \\
\hline LDR & 75.36 & 63.72 & 59.14 & 56.91 & 67.88 \\
\hline ВOPO & 83.00 & 85.00 & 91.00 & 92.14 & 107.99 \\
\hline ROA & 2.81 & 2.73 & 1.47 & 1.21 & -1.21 \\
\hline
\end{tabular}


Berdasarkan data tersebut, terjadi penurunan rasio LDR di tahun 2014 sampai dengan tahun 2017. LDR meningkat kembali pada tahun 2018. Rata-rata LDR dari tahun 2014-2018 adalah sebesar 64.60\%. Angka tersebut masih berada dibawah harapan Bank Indonesia. Karena mengingat kembali tentang Peraturan Bank Indonesia Nomor 17/11/PBI/2015 menyatakan bahwa batas bawah LDR sebesar 78\% dan batas atasnya sebesar $92 \%$.

Rasio BOPO dari tahun 2014-2018 terus mengalami peningkatan, bahkan pada tahun 2018, rasio BOPO sebesar 107.99\% melebihi dari ketentuan Surat Keputusan Direksi Bank Indonesia No.30/12/KEP/DIR/1997, maksimum rasio BOPO adalah 100\%.

Sedangkan untuk rasio ROA dari Tahun 2014-2018, setiap tahun mengalami penurunan. Bahkan pada tahun 2018 rasio ROA bernilai minus yaitu sebesar (1.21\%). Nilai ini juga tidak sesuai dengan ketentuan SK/DIR/BI/NO.30/12/KEP/DIR/1997, yang menyatakan kriteria rasio ROA yang sehat adalah sebesar $1,22 \%$ sampai dengan $1,50 \%$.

Berdasarkan penjelasan diatas, penulis tertarik untuk melakukan sebuah penelitian dengan judul "Pengaruh Loan to Deposit Ratio (LDR) dan BOPO Terhadap Profitabilitas Pada PT. BPR. Duta Bali Periode Tahun 2014-2018".

Tujuan Penelitian ini untuk mengetahui pengaruh LDR secara parsial terhadap Profitabilitas pada PT. BPR. Duta Bali Periode Tahun 2014-2018, pengaruh BOPO secara parsial terhadap Profitabilitas pada PT. BPR. Duta Bali periode Tahun 2014-2018, pengaruh LDR dan BOPO secara simultan terhadap Profitabilitas pada PT. BPR. Duta Bali periode Tahun 2014-2018.

\section{METODE PENELITIAN}

Desain Penelitian ini dikategorikan sebagai penelitian kuantitatif, dan diklasifikasikan sebagai jenis penelitian asosiatif kausalitas. Penelitian asosiatif kausalitas merupakan penelitian yang bertujuan untuk mengetahui hubungan sebab akibat antar dua variabel atau lebih yaitu variabel bebas terhadap variabel terikat.

Variabel bebas dalam penelitian ini adalah LDR dan BOPO, sedangkan untuk variabel terikatnya adalah ROA.

Obyek penelitian adalah LDR, BOPO dan ROA dari laporan keuangan PT. BPR. Duta Bali periode Tahun 2014-2018.

Populasi dalam penelitian ini adalah Laporan keuangan PT. BPR. Duta Bali periode tahun 2014-2018.

Teknik pengambilan sampel dalam penelitian ini menggunakan metode judmental sampling, yaitu pengambilan sampel berdasarkan kriteria yang telah dirumuskan terlebih dahulu oleh peneliti.

Berdasarkan sumber data yang digunakan dalam penelitian ini adalah menggunakan data primer. Data primer merupakan data yang didapat dari sumber pertama, baik dari individu atau perseorangan.

Teknik pengumpulan data yang digunakan dengan wawancara, observasi atau pengamatan langsung dan studi dokumentasi

Teknik analisis data pada penelitian ini menggunakan teknik analisis data regresi linier berganda (multiple regression analysis). Yang terdiri dari Uji Asumsi Klasik, Uji Regresi Linier Berganda, Uji Autokorelasi, Uji Multikolinearitas, Uji Heteroskedastisita, Uji Normalitas, Analisis Determinasi, , Uji Signifikan Simultan (F-tes), Uji Signifikan Parsial (t-tes).

\section{HASIL PENELITIAN}

\section{Statistik Deskriptif.}

Statistik Deskriptif digunakan untuk memberikan gambaran atau deskriptif suatu data yang dilihat dari nilai rata-rata (mean), nilai minimum, nilai maksimum, dan nilai dari data penelitian. Hasil uji statistik deskriptif disajikan pada Tabel 4.2 sebagai berikut: 
Tabel 2

Hasil Uji Statistik Deskriptif

Descriptive Statistics

\begin{tabular}{|l|r|r|r|r|r|}
\hline & $\begin{array}{c}\text { N } \\
\text { (Tahun) }\end{array}$ & Minimum & Maximum & Mean & $\begin{array}{c}\text { Std. } \\
\text { Deviation }\end{array}$ \\
\hline LDR & 5 & 56.91 & 75.36 & 64.6020 & 7.35286 \\
BOPO & 5 & 83.00 & 107.99 & 91.8260 & 9.83042 \\
Profitabilitas & 5 & -1.21 & 2.81 & 1.4020 & 1.62866 \\
Valid N & 5 & & & & \\
(listwise) & 5 & & & & \\
\hline
\end{tabular}

Sumber:Olah data SPSS 24.0 for windows

\section{Uji Asumsi Klasik.}

Model regresi dikatakan model yang baik apabila dalam model tersebut bebas dari asumsi klasik statistik. Suatu model regresi linear berganda secara teoritis akan menghasilkan nilai parameter penduga yang tepat bila memenuhi persyaratan asumsi klasik regresi, yaitu: uji normalitas, multikolinearitas, dan heteroskedastisitas.

Adapun hasil analisis menggunakan grafik histogram dan normal probability plot ditampilkan pada Gambar 4.2 dan Gambar 4.3 berikut:

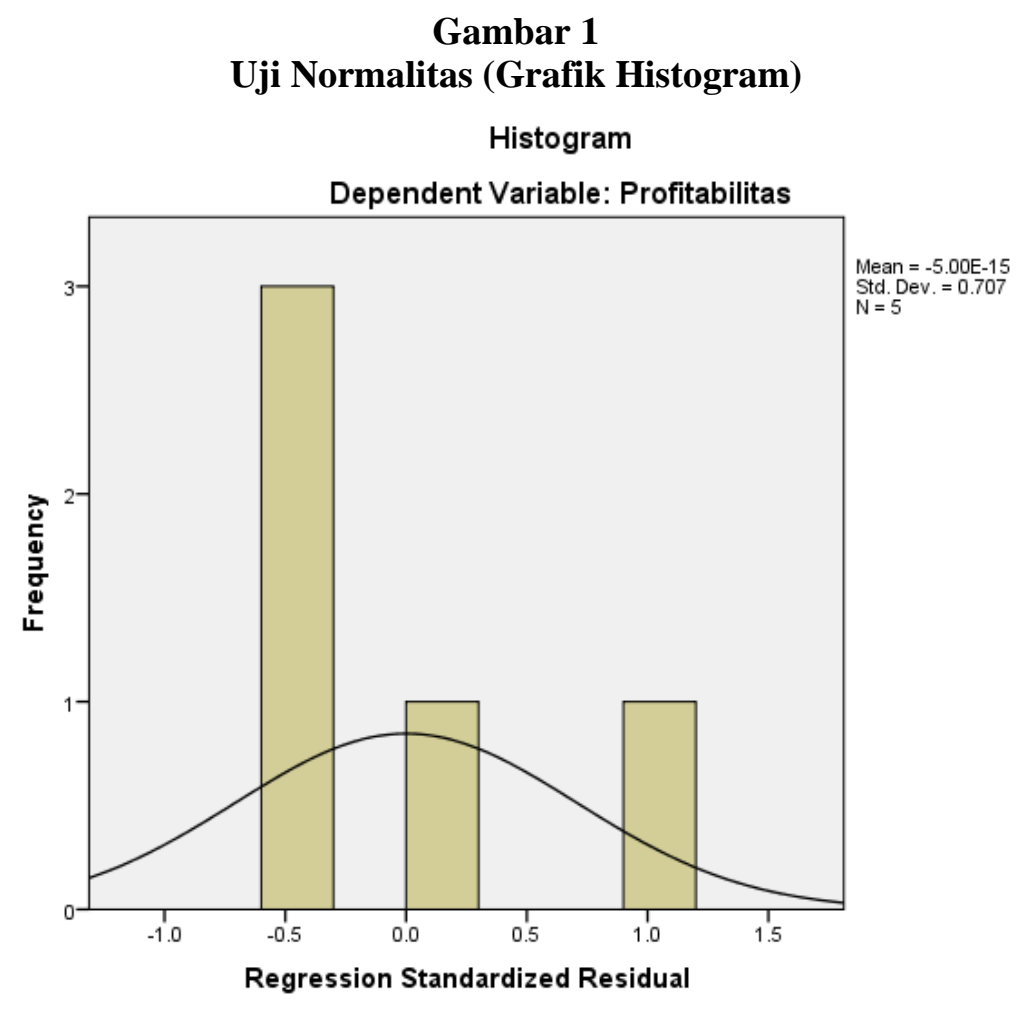

Sumber:Olah data SPSS 24.0 for windows

Grafik histogram yang ditunjukkan pada Gambar 1 menunjukkan bahwa adanya pola distribusi normal sebab memperlihatkan grafik yang mengikuti sebaran kurva normal yang ditunjukkan dengan kurva yang berbentuk lonceng menghadap ke atas. 


\section{Gambar 2}

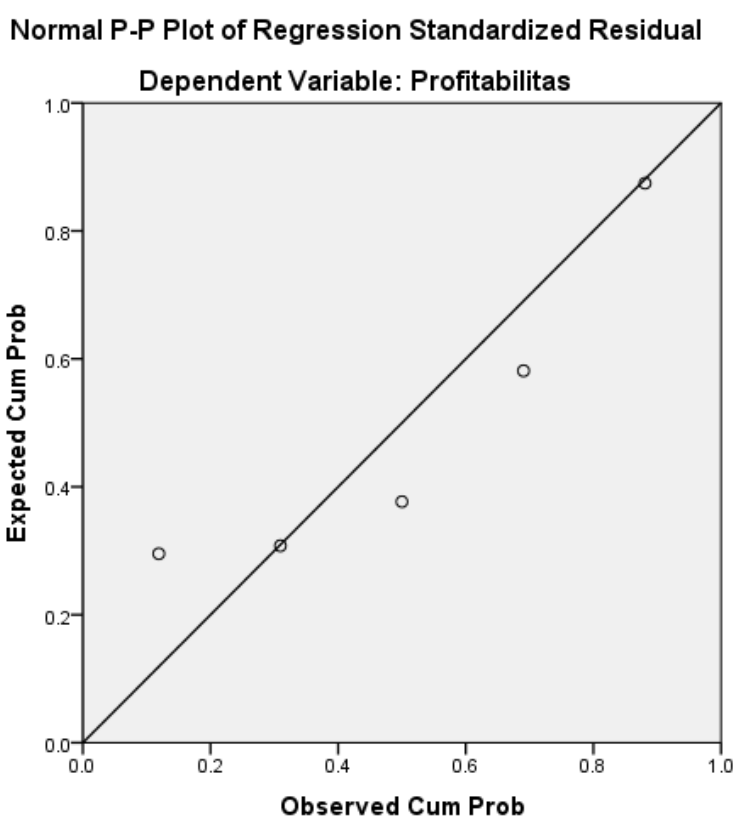

Uji Normalitas (Normal ProbabilityPlot)

Sumber:Olah data SPSS 24.0 for windows

Grafik normal probability plot yang ditunjukkan pada Gambar 2, menunjukkan bahwa adanya pola distribusi normal dimana data berupa plot menyebar disekitar garis diagonal dan mengikuti arah garis diagonal.

Selain menggunakan analisis grafik tersebut, uji normalitas juga dilakukan melalui analisis OneSample Kolmogorov-Smirnov pada uji non parametrik. Adapun hasil uji One-Sample Kolmogorov-Smirnov dapat ditampilkan dalam Tabel 4.3.

\section{Tabel 3}

Uji Normalitas (One-Sample Kolmogorov-Smirnov)

One-Sample Kolmogorov-Smirnov Test

\begin{tabular}{|ll|r|}
\hline & & $\begin{array}{r}\text { Unstandardiz } \\
\text { ed Residual }\end{array}$ \\
\hline $\mathrm{N}$ & Mean & 5 \\
Normal Parameters & .000 \\
& Std. & .12867826 \\
Most Extreme & Deviation & .271 \\
Differences & Absolute & .271 \\
Kolmogorov-Smirnov Z & Positive & -.224 \\
Asymp. Sig. (2-tailed) & & .607 \\
\end{tabular}

a. Test distribution is Normal.

b. Calculated from data.

Berdasarkan uji normalitas dengan menggunakan One-Sample Kolmogorov-Smirnov Test yang ditampilkan pada Tabel 3 tersebut menunjukkan bahwa besarnya nilai Kolmogorov-Smirnov adalah sebesar 0,855. Nilai Kolmogorov-Smirnov tersebut lebih besar dibandingkan dengan nilai Kolmogorov-Smirnov tabel sebesar 0,05 maka $\mathrm{H}_{\mathrm{o}}$ diterima yang mengindikasikan bahwa data yang digunakan pada penelitian ini terdistribusi normal, sehingga dapat disimpulkan bahwa model memenuhi asumsi normalitas. 
Hasil Uji multikolinearitas dapat dilihat dari tabel 4

Tabel 4 Uji Multikolinieritas (Tolerance dan Variance Inflation Factor)

\begin{tabular}{|c|c|c|c|}
\hline \multicolumn{4}{|c|}{ Coefficients $^{\mathrm{a}}$} \\
\hline \multirow{2}{*}{\multicolumn{2}{|c|}{ Model }} & \multicolumn{2}{|c|}{$\begin{array}{l}\text { Collinearity } \\
\text { Statistics }\end{array}$} \\
\hline & & Tolerance & VIF \\
\hline \multirow{2}{*}{1} & LDR & .296 & 3.382 \\
\hline & BOPO & .296 & 3.382 \\
\hline
\end{tabular}

a. Dependent Variable: Profitabilitas

Berdasarkan Tabel 4 tersebut ditunjukkan bahwa tidak terdapat variabel bebas yang memiliki nilai tolerance kurang dari 0.10 dan juga tidak ada variabel bebas yang memiliki nilai VIF lebih dari 10. Maka dari pada itu model regresi bebas dari gejala multikoleniaritas.

Hasil Uji autokorelasi dapat dilihat pada table 5.

Tabel 5 Hasil Uji Autokorelasi Model Summary

\begin{tabular}{|l|r|}
\hline Model & Durbin-Watson \\
\hline 1 & $2.031^{\mathrm{a}}$ \\
\hline
\end{tabular}

a. Predictors: (Constant), BOPO, LDR

b. Dependent Variable: Profitabilitas

Berdasarkan tabel 5, persamaan regresi memiliki nilai DW sebesar 2.031. Jumlah sampel 5 dan terdapat 2 variabel bebas, maka nilai du diperoleh sebesar 1.896 dan nilai 4-du sebesar 2.104 Jadi nilai DW berada diantara nilai du dan nilai 4-du, sehingga persamaan regresi bebas dari adanya autokorelasi.

Hasil Uji heteroskedastisitas dapat dilihat pada tabel 6.

Tabel 6

Uji Heteroskedastisitas (Uji Glesjer)

Coefficients $^{\mathrm{a}}$

\begin{tabular}{|c|c|c|c|c|c|}
\hline \multirow[t]{2}{*}{ Model } & \multicolumn{2}{|c|}{$\begin{array}{l}\text { Unstandardized } \\
\text { Coefficients }\end{array}$} & $\begin{array}{l}\text { Standardized } \\
\text { Coefficients }\end{array}$ & $\mathrm{t}$ & Sig. \\
\hline & $\mathrm{B}$ & Std. Error & Beta & & \\
\hline (Constant) & .943 & 1.120 & & .842 & .48 \\
\hline LDR & -.004 & .009 & -.410 & -.424 & .71 \\
\hline BOPO & -.007 & .007 & -.973 & -1.005 & .42 \\
\hline
\end{tabular}

a. Dependent Variable: abs_res

Berdasarkan Tabel 6 tersebut, ditunjukkan bahwa masing-masing model memiliki nilai signifikansi lebih besar dari 5\%. Hal ini menunjukkan bahwa variabel bebas yang digunakan pada penelitian ini tidak berpengaruh secara signifikan terhadap variabel terikatnya yaitu absolute error, maka dari itu, penelitian ini bebas dari gejala heteroskedastisitas. Adapun pengujian melalui grafik scatterplot ditunjukkan pada Gambar 3 berikut. 


\section{Gambar 3 \\ Uji Heteroskedastisitas (Grafik Scatterplot)}

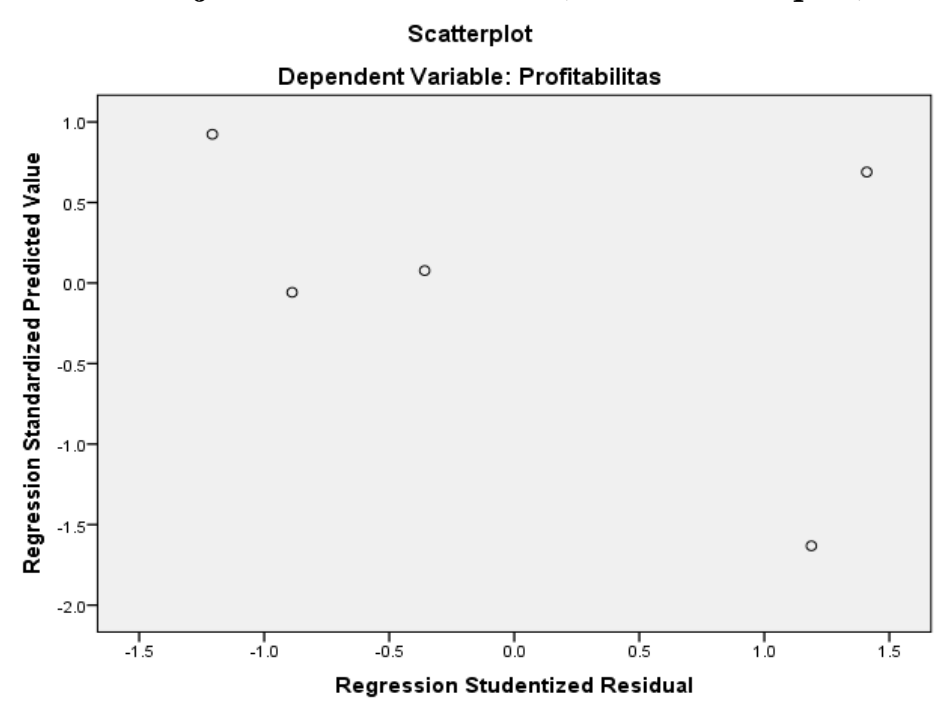

Berdasarkan Gambar 3 ditunjukkan bahwa titik-titik pada gambar menyebar secara acak baik diatas maupun dibawah angka 0 pada sumbu Y. Oleh karena itu, dapat disimpulkan bahwa tidak terdapat gejala heteroskedastisitas pada model regresi ini.

\section{Analisis Regresi Linier Berganda.}

Hasil analisis regresi linear berganda dapat dilihat pada tabel 7.

Tabel 4.7

Hasil Analisis Regresi Linear Berganda

Coefficients $^{\mathrm{a}}$

\begin{tabular}{|c|c|c|c|c|c|c|}
\hline \multirow{2}{*}{\multicolumn{2}{|c|}{ Model }} & \multicolumn{2}{|c|}{$\begin{array}{l}\text { Unstandardized } \\
\text { Coefficients }\end{array}$} & \multirow{2}{*}{\begin{tabular}{|c}
$\begin{array}{c}\text { Standardize } \\
\text { d } \\
\text { Coefficient } \\
\text { s }\end{array}$ \\
Beta \\
\end{tabular}} & \multirow[t]{2}{*}{$\mathrm{t}$} & \multirow[t]{2}{*}{ Sig. } \\
\hline & & B & Std. Error & & & \\
\hline \multirow{3}{*}{1} & $\begin{array}{c}\text { (Constan } \\
\text { t) }\end{array}$ & 15.582 & 2.910 & & 5.355 & .033 \\
\hline & LDR & .008 & .023 & .036 & .353 & .758 \\
\hline & BOPO & -.160 & .017 & -.966 & -9.404 & .011 \\
\hline
\end{tabular}

a. Dependent Variable: Profitabilitas

Berdasarkan Tabel 4.7 dapat ditulis persamaan regresi linear berganda sebagai berikut: $\mathrm{Y}=15.582+0.008 \mathrm{X}_{1}-0.160 \mathrm{X}_{2}$

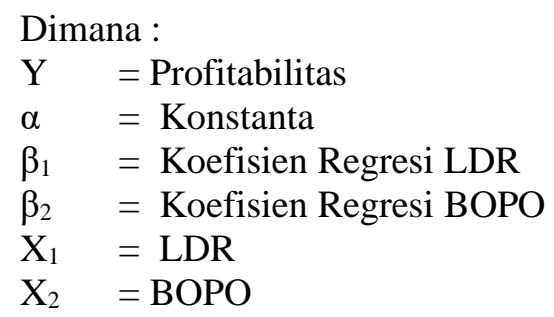

Persamaan regresi linear berganda tersebut menunjukkan arah masing-masing variabel bebas terhadap variabel terikatnya. Persamaan regresi linear berganda tersebut dapat diuraikan sebagai berikut :

1) Nilai Konstanta $(\alpha)$ adalah 15.582. Artinya, jika LDR dan BOPO nilainya adalah 0 (nol) maka tingkat Profitabilitas Pada PT. BPR. Duta Bali Periode Tahun 2014-2018 nilainya positif yaitu sebesar 15.582. 
2) Nilai koefisien regresi variable LDR $\left(\beta_{1}\right)$ bernilai positif, yaitu 0.008. Artinya, bahwa setiap peningkatan LDR sebesar Rp1 maka tingkat Profitabilitas pada PT. BPR. Duta Bali Periode Tahun 2014-2018 juga akan meningkat sebesar Rp0.008 dengan asumsi variable independen lain nilainya tetap.

3) Nilai koefisien regresi variable BOPO $\left(\beta_{2}\right)$ bernilai negatif yaitu -0.160. Artinya, bahwa setiap peningkatan BOPO sebesar Rp1 pada PT. BPR. Duta Bali Periode Tahun 2014-2018, maka Profitabilitas akan mengalami penurunan sebesar 0.160 dengan asumsi variable independen lainnya tetap.

\section{Analisis Determinasi.}

Analisis determinasi dilakukan untuk mengetahui sejauh mana variasi variabel bebas yaitu $X_{1}$ (LDR), $\mathrm{X}_{2}$ (BOPO) terhadap variabel Profitabilitas (Y). berdasarkan hasil spss yang dapat dilihat pada Tabel 4.8 .

\section{Tabel 8}

Determinasi

Model Summary ${ }^{\mathrm{b}}$

\begin{tabular}{|l|r|r|r|r|}
\hline Model & \multicolumn{1}{|c|}{$\mathrm{R}$} & R Square & $\begin{array}{c}\text { Adjusted R } \\
\text { Square }\end{array}$ & $\begin{array}{l}\text { Std. Error of } \\
\text { the Estimate }\end{array}$ \\
\hline 1 & $.997^{\mathrm{a}}$ & .994 & .988 & .18198 \\
\hline
\end{tabular}

a. Predictors: (Constant), BOPO, LDR

b. Dependent Variable: Profitabilitas

Berdasarkan Tabel 8 tersebut dapat diketahui bahwa nilai adjr square $\left(\left(\mathrm{r}^{2}\right)=0,988\right.$ Adapun analisis menggunakan rumus sebagai berikut:

$\mathrm{D}=\operatorname{adjr}^{2} \times 100 \%$

$\mathrm{D}=0,988 \mathrm{x} 100 \%$

$\mathrm{D}=98,8 \%$

Berdasarkan hasil tersebut diketahui bahwa nilai $\mathrm{R}^{2}=98.8 \%$, yang berarti bahwa sebesar $98.8 \%$ Profitabilitas Pada PT. BPR. Duta Bali Periode Tahun 2014-2018 dipengaruhi oleh variabel LDR ( $\left.\mathrm{X}_{1}\right)$, BOPO $\left(\mathrm{X}_{2}\right)$, dan sisanya sebesar $1.2 \%$ dipengaruhi oleh variabel lain yang tidak diteliti pada penelitian ini.

\section{Hasil Uji F.}

Hasil Uji F dapat dilihat pada tabel 9.

\section{Tabel 9 \\ Tabel 9}

ANOVA $^{\mathbf{a}}$

\begin{tabular}{|ll|r|r|r|r|l|}
\hline \multicolumn{1}{|l|}{ Model } & \multicolumn{1}{|c|}{$\begin{array}{c}\text { Sum of } \\
\text { Squares }\end{array}$} & df & Mean Square & F & Sig. \\
\hline \multirow{2}{*}{1} & Regression & 10.544 & 2 & 5.272 & 159.195 & $.006^{\mathrm{b}}$ \\
& Residual & .066 & 2 & .033 & & \\
& Total & 10.610 & 4 & & & \\
\hline
\end{tabular}

a. Dependent Variable: Profitabilitas

b. Predictors: (Constant), BOPO, LDR

Hasil Uji statistic $\mathrm{F}$ (F-test) diperoleh $\mathrm{F}_{\text {hitung }}\left(159.195>\mathrm{F}_{\text {tabel }} \quad\right.$ (19.00) dengan nilai signifikansi $\mathrm{F}$ adalah $0.006<0.05$, maka $\mathrm{H}_{0}$ ditolak. Hal ini berarti bahwa variabel LDR $\left(\mathrm{X}_{1}\right)$, variabel BOPO $\left(\mathrm{X}_{2}\right)$, secara simultan berpengaruh secara signifikan terhadap Profitabilitas (Y) Pada PT. BPR. Duta Bali Periode Tahun 2014-2018.

\section{Hasil Uji t.}

Hasil uji parsial (uji t) dapat dilihat pada tabel 10. 


\begin{tabular}{|c|c|c|c|}
\hline \multicolumn{4}{|c|}{$\begin{array}{c}\text { Tabel 10 } \\
\text { Hasil Uji t }\end{array}$} \\
\hline Variabel & $\begin{array}{l}\text { Unstandardized } \\
\text { Coefficients Beta }\end{array}$ & t hitung & Sig. \\
\hline LDR & 0.008 & 0.353 & 0.758 \\
\hline BOPO & -0.160 & -9.404 & 0.011 \\
\hline
\end{tabular}

Hasil uji hipotisis pengaruh Variabel LDR $\left(\mathrm{X}_{1}\right)$ terhadap Profitabilitas berdasarkan tabel 10 di atas dapat dijelaskan bahwa $\mathrm{t}_{\text {hitung }}(0.353)<\mathrm{t}_{\text {tabel }}(4.303)$ dengan tingkat signifikansi $0.758>0.05$, sehingga $\mathrm{H}_{0}$ diterima dan $\mathrm{H}_{\mathrm{a}}$ ditolak yang berarti bahwa variabel LDR berpengaruh positif tidak signifikan terhadap Profitabilitas. Hipotesis pertama ditolak.

Hasil Uji hipotesis pengaruh variabel BOPO $\left(\mathrm{X}_{2}\right)$ terhadap Profitabilitas adalah sebagai berikut: bahwa $t_{\text {hitung }}-9.404<\mathrm{t}_{\text {tabel }}-4.303$ dengan tingkat signifikansi $0.011<0.05$, sehingga $\mathrm{H}_{0}$ ditolak dan $\mathrm{H}_{\mathrm{a}}$ diterima yang berarti bahwa variabel BOPO berpengaruh negatif signifikan terhadap Profitabilitas. Koefisien regresi $\beta 2$ (variabel BOPO) sebesar -0.160 , menunjukkan bahwa meningkatnya BOPO maka akan menurunkan Profitabilitas Pada PT. BPR. Duta Bali Periode Tahun 2014-2018. Hipotesis kedua diterima.

\section{PENUTUP}

\section{Simpulan}

Berdasarkan hasil analisis data dan pembahasan, maka didapat simpulan hasil penelitian adalah sebagai berikut :

a. LDR berpengaruh positif tidak signifikan secara parsial terhadap Profitabilitas Pada PT. BPR. Duta Bali Periode Tahun 2014-2018, dengan nilai $t_{\text {hitung }} 0.353<\mathrm{t}_{\text {tabel }} 4.303$ dengan tingkat signifikansi $0.758>0.05$

b. BOPO berpengaruh negatif dan signifikan secara parsial terhadap Profitabilitas Pada PT. BPR. Duta Bali Periode Tahun 2014-2018, dengan nilai $t_{\text {hitung }}-9.404<\mathrm{t}_{\text {tabel }}-4.303$ dengan tingkat signifikansi $0.011<$ 0.05 .

c. LDR, BOPO berpengaruh signifikan secara simultan terhadap Profitabilitas Pada PT. BPR. Duta Bali Periode Tahun 2014-2018, dengan nilai $F_{\text {hitung }} 159.195>F_{\text {tabel }} 19.00$ dan nilai signifikansi $F$ adalah 0.006 $<0.05$.

\section{Saran-saran}

Dalam usaha meningkatkan Profitabilitas maka disarankan bagi Pada PT. BPR. Duta Bali Periode Tahun 2014-2018 sebagai berikut :

a. Loan to Deposit Ratio atau LDR merupakan perbandingan total kredit terhadap Dana Pihak Ketiga (DPK) yang dihimpun oleh bank. Rasio ini akan menunjukan tingkat kemampuan bank dalam menyalurkan dananya yang berasal dari masyarakat (berupa: giro, tabungan, deposito berjangka, sertifikat deposito berjangka dan kewajiban segera lainnya) dalam bentuk kredit Bank yang efisien dalam menekan biaya operasional dapat meningkatkan profitabilitas. Bank Indonesia menetapkan besarnya rasio BOPO tidak melebihi $100 \%$, apabila melebihi 100\%, maka bank tersebut dikategorikan tidak efisien. Menurut Bank Indonesia, Efisiensi operasional diukur dengan membandingkan total biaya operasional dengan total pendapatan operasional atau disebut dengan BOPO.

b. Bagi penelitian selanjutnya diharapkan mampu menambah variabel- variabel yang dapat mempengaruhi Profitabilitas, serta mampu untuk memperluas ruang lingkup penelitian yang tidak hanya terbatas pada Pada PT. BPR Duta Bali atau dapat juga mengganti lokasi penelitian yang tidak hanya terfokus pada satu lokasi penelitian, sehingga memberikan suatu pandangan yang lebih dan mampu diimplementasikan secara umum.

\section{DAFTAR PUSTAKA}

Agus Sartono.(2010). Menejemen Keuangan Teori dan Aplikasi. Edisi keempat, BPFE Yogyakarta

Bank Indonesia.(2011). Surat Edaran Bank Indonesia Nomor 13/24/DPNP Perihal Penilaian Tingkat Kesehatan Bank Umum. www.bi.go.id. 
Dendawijaya, Lukman.(2009). Manajemen Perbankan. Jakarta: Ghalia Indonesia.

Fahmi, Irham.(2010). Manajemen Resiko. Bandung: Alfabeta

Ghozali, Imam.(2016). Aplikasi Analisis Multivariete Dengan Program IBM SPSS 23 (Edisi 8). Cetakan ke VIII. Semarang : Badan Penerbit Universitas Diponegoro

Hasibuan, Malayu S.P.(1996). Manajemen Dasar, Pengertian dan Masalah, Edisi

Kedua, Jakarta: PT Toko Gunung Agung

Ida ayu Adiatmayani Peling dan Ida Bagus Panji Sedana (2018). dengan judul: Pengaruh LDR, NPL, Dan BOPO Terhadap Profitabilitas Pada PT.BPD Bali Periode Tahun 2009-2016, dalam E-Jurnal Manajemen Unud, Vol.7, No.6,2018:2999-3026, ISSN:2302-8912

Kasmir.(2002). Bank dan Lembaga Keuangan Lainnya. Edisi Revisi 2002.

Jakarta: PT. RAJAGRAFINDO PERSADA.

Kasmir.(2008). Bank dan Lembaga Keuangan Lainnya. Edisi Revisi 2008. Jakarta:PT. RAJAGRAFINDO PERSADA

Kasmir.(2010). Analisis Laporan Keuangan. Jakarta: PT Raja Grafindo Persada.

Kasmir.(2012), Analisis Laporan Keuangan. Jakarta : PT. Raja Grafindo Persada

Kasmir.(2014). Bank dan Lembaga Keuangan Lainnya. Edisi Revisi, Cetakan keempat belas, PT. RajaGrafindo Persada, Jakarta.

Luh Putu Sukma Wahyuni Pratiwi dan NI Luh Putu Wiagustini (2015). Dengan judul : Pengaruh CAR, BOPO, NPL, Terhadap Profitabilitas, dalam E-Jurnal Manajemen Unud, Vol.5, No.4, 2015:2137-2166

Muhammad Farrul Rozi Syafi'i.(2016). Dengan judul : Pengaruh Risiko Kredit, Risiko Pasar,Risiko Operasional dan Risiko Likuiditas Terhadap Profitabilitas Perbankan

Ni Wayan Wita Capriani dan I Made Dana (2016). Dengan judul : Pengaruh Risiko Kredit Risiko Operasional Dan Risiko Likuiditas Terhadap Profitabilitas BPR Di Kota Denpasar, dalam E-Jurnal Manajemen Unud, Vol.5,No.3, 2016:1486-1512, ISSI:2302-8912

Undang-Undang Nomor 10 Tahun 1998 tentang Perubahan atas Undang-Undang Nomor 7 Tahun 1992 tentang Perbankan

Pandia, Frianto.(2012). Manajemen Dana dan Kesehatan Bank. Jakarta: Rineka Cipta

Peraturan Bank Indonesia Nomor 17/11/PBI/2015 tentang Perubahan Atas Peraturan bank Indonesia Nomor 15/15/PBI/2013 tentang Giro Wajib Minimum Bank Umum dalam Rupiah dan Valuta Asing Bagi Bank Umum Konvensional.

Priyatno, (2018). SPSS Panduan Mudah Olah Data bagi Mahasiswa dan Umum,Penerbit: Andi, Yogyakarta

Riyadi, Slamet.(2006). Banking Assets and Liability Management, edisi ketiga, Penerbit: Fakultas Ekonomi Universitas Indonesia, Jakarta.

Sugiarto.(2016). Metodologi Penelitian Bisnis, Edisi I. Yogyakarta: Andi (Anggota IKAPI).

Surat Keputusan Bank Indonesia No. 30/12/KEP/DIR tanggal 30 April 1997 tentang Tata Cara Penilaian Tingkat Kesehatan Bank Perkreditan Rakyat".Diakses pada tanggal 11 September 2013 dari http://www.bi.go.id

Slamet Fajar, Sunarto.(2017). Dengan judul: Pengaruh CAR, LDR, NPL, BOPO, Terhadap Profitabilitas Bank

Tim Penyusun Universitas Ngurah Rai.(2018). Panduan Penyusun Proposal Penelitian Dan Skripsi Tahun 2018. Denpasar: Universitas Ngurah Rai Denpasar 